\title{
Evaluation of multiple cation/anion perovskite solar cells through life cycle assessment
}

\author{
Jaume-Adrià Alberola-Borràs, ${ }^{\mathrm{a}, \mathrm{b}}$ Rosario Vidal, ${ }^{\mathrm{a}, *}$ Iván Mora-Seró ${ }^{\mathrm{b}, *}$ \\ a Grupo de Ingeniería de Diseño (GID), Departament d'enginyeria mecànica i construcció, \\ Universitat Jaume I, Av. SosBaynat s/n, 12071 Castelló, Spain \\ ${ }^{b}$ Institute of Advanced Materials (INAM), Universitat Jaume I, Av. Sos Baynat, s/n, 12006 \\ Castelló, Spain
}

Electronic supplementary information (ESI) available: Inventory data, impact scores, further analyses, and abiotic depletion characterisation factor update.

*Corresponding author. E-mail: vidal@uji.es; sero@uji.es. Tel: +34 964387552

\begin{abstract}
After the great initiation of perovskite as a photovoltaic material, laboratory efficiencies similar to other photovoltaic technologies already commercialised have been reached. Consequently, recent research interests on perovskite solar cells try to address the stability improvement as well as make its industrialisation possible. Record efficiencies in perovskite solar cells (PSCs) have been achieved using as active material a multiple cation/anion perovskite by combining methylammonium (MA) and formamidinium (FA), but also $\mathrm{Cs}$ cation and $\mathrm{I}$ and $\mathrm{Br}$ as anions, materials that also have demonstrated a superior stability. Herein, the environmental performance of the production of such perovskite films was evaluated via life cycle assessment. Our study points out that multiple cation/anion perovskite films show major detrimental environmental impacts for all categories assessed, except for abiotic depletion potential, when they are compared with a canonical perovskite $\mathrm{MAPbl}_{3}$. In addition, a closer analysis of the materials utilised for the synthesis of the different multiple cation perovskites compositions revealed that lead halide reagents and chlorobenzene were the most adverse compounds in terms of impact. However, the former is used in all the perovskite compositions and the later can be avoided by the use of alternative fabrication methods to anti-solvent. To this extent, FAl, with the current synthesis procedures, is the most determining compound as it increases significantly the impacts and the cost in comparison with MAI. A further economic analysis, exposed that multiple cation perovskites need a significantly higher photoconversion efficiency to produce the same payback times than canonical perovskite.
\end{abstract}




\section{Introduction}

Perovskite solar cells (PSCs) have experienced an unprecedented rise since they were discovered in $2009^{1}$ and constitute a promising technology to collect energy from sun in the near future. Fundamental reasons of such success are an easy and cheap deposition of perovskite combined with efficiencies (PCE) comparable to those of the most expensive monocrystalline silicon solar cells. ${ }^{2}$ For now, perovskite compositions, solvents and deposition processes are under optimisation. ${ }^{3-5}$ However, in order to produce them at a large scale, stability and reproducibility issues must be overcome..$^{6-9}$

Thus far, much research on PSCs has been oriented towards compositional engineering. ${ }^{3-5,10}$ Perovskites with outstanding photovoltaic properties have a distinctive structure, composed by three atoms according to the formula $A B X_{3}$, where $A$ corresponds to a monovalent organic/inorganic cation, $\mathrm{B}$ corresponds to a divalent inorganic cation (commonly $\mathrm{Pb}$ ) and $\mathrm{X}$ corresponds to a halide anion $(\mathrm{Cl}, \mathrm{Br}$ and $\mathrm{I})$. As for the monovalent cationic position $(\mathrm{A})$, the most efficient perovskite compositions introduce formamidinium (FA) cation along with the traditional methylammonium (MA) cation and also $\mathrm{Br}$ partially substitutes I anion ${ }^{4,5,11-14}$ with published efficiencies as high as $22.1 \%{ }^{3}$ Recently, a caesium inorganic monovalent cation has shown also good results when combined with MA and FA in the perovskite structure. Actually, the three cations combined performed an enhanced power conversion efficiency (PCE) of $21.1 \% .{ }^{15}$ Not only that, but high reproducibility was achieved and the efficiency after $250 \mathrm{~h}$ was found quite stable, performing an efficiency of $18 \%$.

Lately, the so-called anti-solvent method has been used extensively to deposit high quality perovskite layers. ${ }^{14-17}$ This method is implemented into the conventional spin-coating method, which can use Dimethylformamide (DMF), dimethylsulfoxide (DMSO) or $\gamma$-butyrolactone (GBL) as solvents for perovskite precursors. What makes this method different is the addition of a drop of a non-polar solvent as chlorobenzene (CB) into the mixture during the spin-coating stage in order to force the formation of nucleation centres.

Chemical and optoelectronic properties of the three cations are notably different. On one hand, band gap of $\mathrm{FAPbl}_{3}$ is closer to the theoretical optimum. ${ }^{18}$ Yet, pure $\mathrm{FAPbl}_{3}$ presents low structural stability at room temperature as a disadvantage ${ }^{11,19}$ thus needing $\mathrm{MAPbl}_{3}$ to reach a fair balance between efficiency and stability. On the other hand, inclusion of Cs enhances the stability of Br PSCs. ${ }^{20,21}$ However, caesium iodine perovskites forming $\mathrm{CsPbl}_{3}$ could provide a band gap of $1.73 \mathrm{eV}$, which is relatively close to the aforementioned theoretical optimum, but its bulk perovskite phase is solely stable at temperatures above $300{ }^{\circ} \mathrm{C}^{22}$

Apparently, combining MA and FA cations also combines their advantages while avoids their disadvantages. Nevertheless, a PSC with FA and Cs has been reported with enhanced thermal and humidity stability. ${ }^{23} \mathrm{Cs}$ assists the crystallisation of FA faster and more effectively than MA does, due to a superior size difference. ${ }^{15}$ Although Cs may be deemed a low abundant element, its presence on earth crust is comparable to other large-scale produced elements like $\mathrm{Sn}^{20}$ thus demonstrating that usage of $\mathrm{Cs}$ is feasible. Indeed, the sufficient abundance in Earth's crust of Cs compared with the rest of the elements is illustrated in the chart elaborated 
by the U.S. Geological Survey. ${ }^{24}$ Furthermore, Cs concentration in the Earth's crust is signally larger than that of other elements already used in photovoltaics, namely cadmium, tellurium, selenium or indium.

Environmental analyses of PSCs via life cycle assessment (LCA) methodology have been reported to ensure an environmentally safer PSCs development and assist PSCs technology growth while respecting the environment. ${ }^{25-29}$ Recently, a comparison of PSCs with silicon solar cells and a tandem with both perovskite and silicon was implemented. ${ }^{30}$ Furthermore, the four most common methods to produce PSCs were environmentally revised by us. ${ }^{31}$ This study also assessed a PSCs regeneration method previously proposed ${ }^{32,33}$ applied to the four production methods considered.

Other studies addressed the inclusion of Cs and FA in PSCs. For instance, a LCA was individually applied to the whole life cycle of modules of five different types of perovskite, such as $\mathrm{MAPbl}_{2} \mathrm{Cl}, \mathrm{MAPbl}_{3}, \mathrm{FAPbl}_{3}, \mathrm{CsPbl}_{3}, \mathrm{MASnl}_{3-\mathrm{x}} \mathrm{Br}_{\mathrm{x}}{ }^{34}{ }^{4}$ In this work, $\mathrm{MAPbl}$ and $\mathrm{FAPbl}_{3}$ arose as the most harmful perovskites. However, results of the comparison of perovskites were clouded by the rest of the layer forming devices, such as the cathode and the anode made of fluorinedoped tin oxide (FTO). Another study collated a conventional $\mathrm{MAPbX}_{3}$ and a more stable $\mathrm{CsFAPbX}_{3}$ with other photovoltaic technologies. ${ }^{35}$

The aim of this work is to evaluate the ongoing trend of compositional engineering in PSCS through LCA from cradle to gate. Therefore, the focus is solely set on the perovskite layer. Furthermore, as layers apart from perovskite layer would be roughly the same for every PSC studied, focusing the comparison on perovskite layer is more meaningful. By isolating the perovskite layer, clear results of the environmental performance of the different compositions of perovskites combining the three Cs, FA and MA cations, as well as the reagents that contain them, are obtained here for the first time. Herein, the four compositions reported on the manuscript of Saliba et $\mathrm{al}^{15}$ are contrasted with a canonical $\mathrm{MAPbl}_{3}$ perovskite synthesised and deposited according to Noh et al. ${ }^{36}$ As a consequence, the corresponding deposition methods for each type of perovskite are also contrasted. For a more realistic determination of the energy consumption, it has been directly measured for the preparation of cells at laboratory scale. Energy used in the method to synthesise multiple cation/anion perovskite was obtained by measuring the consumption in a laboratory environment. On the other hand, the energy consumption for the synthesis of canonical perovskite was taken from our previous study, based also in the direct measurement. ${ }^{31}$ In the section 2.2 of the supplementary information, an update of the characterisation factor of Cs for abiotic depletion potential category from literature of 2002 with another estimated from data of 2017 is developed. Furthermore, the usage of materials for the synthesis of the multiple cation/anion perovskite is analysed to find the responsible compounds of the four compositions impact. A final economic analysis of the materials complements this assessment. Together with the economic cost of the materials, this analysis presents an economic payback time analysis of the materials used for the synthesis of all perovskites. Outcomes of this study are intended to support scientific community to develop PSCs with the highest efficiencies and stabilities in a safe and environmentally-respectful way, thus fulfilling one of the objectives of this technology. 
Thereby, after this study PSCs are expected to be one step closer to industrial scale production.

\section{Materials and methods}

\subsection{Goal and scope definition}

Fundamental research on PSC is mainly focusing on the efficiency enhancement and on the increase of long term stability. This study is intended to assist researchers in the realm of perovskite-based photovoltaics on issues less investigated but significantly important for the further development of an industrial technology as the effect of composition in cell impacts and cost. For this purpose, four different combinations of the inorganic cation Cs with the most used organic cations FA and MA using $\mathrm{Br} / \mathrm{I}$ anions were compared with the canonical $\mathrm{MAPbl}_{3}$ perovskite. Impacts generated by the perovskite layer were assessed from cradle to gate using LCA as tool. A functional unit of $1 \mathrm{~cm}^{2}$ of PSC was chosen as representative for the comparison of several compositions of perovskite. It is very important to highlight that, this work solely assesses the perovskite layer deposited, as the rest of the layers (substrate, electron and hole selecting contacts...) are considered to be similar for all the analysed cases and for that reason excluded from the LCA. ${ }^{37,38}$ A detailed effect of these other parts of the cell can be found in our previous LCA study. ${ }^{31}$ The corresponding efficiencies and lifetimes of the PSCs (Table 1) made of the five combinations of perovskite were extracted from the works in which their syntheses are reported. ${ }^{15,36}$

\subsection{System boundary}

In order to compare the environmental performance of the highly efficient and more stable multiple cation/anion perovskite with a canonical perovskite, an LCA was conducted from cradle to gate. Therefore, the steps of the life cycle of PSCs included from the extraction of raw materials to the deposition of the perovskite layer. As in this work just the perovskite layer is studied, the system ends when every step concerning the deposition of the perovskite layer is accounted. Although perovskite is synthesised generally in a nitrogen glove box, its energetic consumption and the nitrogen it uses is dismissed, as it participates in both synthesis processes. Thereby, the deposition methods modelled for this work are described in Figure 1.

As well as in the work of Saliba et al, $^{15}$ a deposition with the anti-solvent method was simulated, which is illustrated in Figure 1a. This method cannot easily be up-scaled for industrial applications, ${ }^{39}$ however we have decided to include it due to its extended use and to determine its impact from the point of view of LCA. In this study, for a perovskite deposition with anti-solvent we consider a first step of spin-coating at $1000 \mathrm{rpm}$ for $10 \mathrm{~s}$ of the reagents with a mixture of (4:1) DMF and DMSO in volume. This step was followed by another spincoating step at $6000 \mathrm{rpm}$ for $20 \mathrm{~s}$, in which $100 \mu \mathrm{l}$ of CB were dropped onto the mixture $5 \mathrm{~s}$

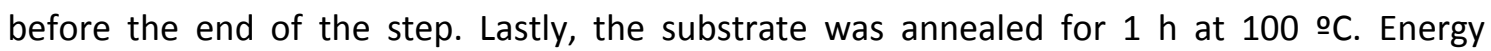
consumption was directly measured from laboratory devices.

The deposition of the canonical perovskite, which is depicted in Figure $1 \mathrm{~b}$, comprised a first stirring of the mixture of $\mathrm{MAl}$ and $\mathrm{Pbl}_{2}$ reagents in $\mathrm{GBL}$ at room temperature for 10 minutes 
and 30 minutes at 70 ㄷ. Then, the mixture was spin-coated at 500 for $5 \mathrm{~s}$ and $2000 \mathrm{rpm}$ for 60 s. Finally, the film was heated for 60 minutes at $100 \stackrel{\circ}{ }$ C. This procedure was extracted from our previous assessment. $^{31}$

a)



b)

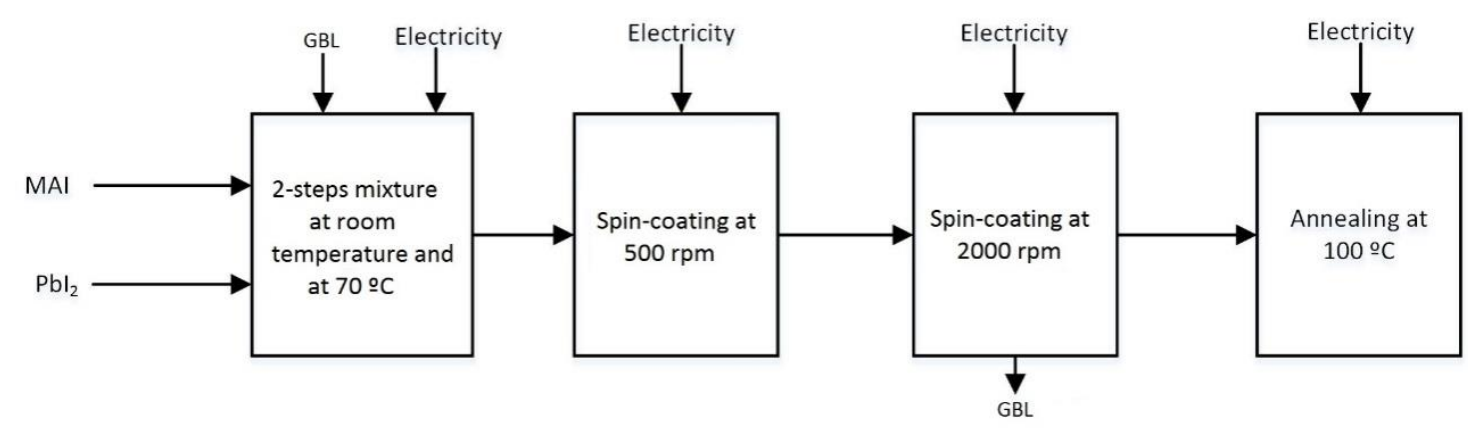

Figure 1. System boundary of the steps involved in the deposition of the perovskite layer of a) deposition route of the multiple cation/anion perovskite through the anti-solvent method and b) deposition route of the canonical perovskite through a simple spin-coating method.

\subsection{Inventory}

Herein, combinations of the three cations and two anions follow a general formula $\left(C s_{x}\left[M A_{0.17} F A_{0.83}\right]_{(1-x)} P b\left[I_{0.83} B r_{0.17}\right]_{3}\right)$, which reached efficiencies around $20 \%$ and a good stability during $250 \mathrm{~h},{ }^{15}$ as shown in Table 1 . As well as in the manuscript, the four combinations used herein were $x=0,0.05,0.10$ and 0.15 , where consequently $x=0$ just containing MA and FA, the combination used for the currently published PSC record. ${ }^{3}$ According to that, the resulting stoichiometric coefficients of each precursor used for the synthesis are clarified in Table 2. As for the canonical perovskite an even mixture of MAI and $\mathrm{Pbl}_{2}$ were considered, ${ }^{36}$ known for being a general recipe from the early days of PSCs.

Table 1.Performance data of PSCs with perovskites containing three compounds in the cationic position ${ }^{15}$ and the canonical perovskite. ${ }^{36}$

\begin{tabular}{|l|l|l|l|l|l|}
\hline & 0.00 & 0.05 & 0.10 & 0.15 & Canonical \\
\hline PCE (\%) & 16.8 & 18.6 & 19.1 & 14.6 & 10.4 \\
\hline Stability (h) & 100 & $250(18 \%)^{*}$ & - & - & - \\
\hline
\end{tabular}

*After $250 \mathrm{~h}$ the efficiency dropped to $18 \%$ 
Table 2.Stoichiometric coefficients of the reagents used for the syntheses of the perovskites compared.

\begin{tabular}{|l|c|c|c|c|c|c|}
\hline Composition & CsI & FAI & MABr & MAI & $\mathbf{P b l}_{2}$ & $\mathbf{P b B r}_{2}$ \\
\hline 0.00 & 0.0000 & 0.8300 & 0.1700 & - & 0.8300 & 0.1700 \\
\hline 0.05 & 0.0500 & 0.7885 & 0.1615 & - & 0.8258 & 0.1743 \\
\hline 0.10 & 0.1000 & 0.7470 & 0.1530 & - & 0.8215 & 0.1785 \\
\hline 0.15 & 0.1500 & 0.7055 & 0.1445 & - & 0.8173 & 0.1828 \\
\hline Canonical & - & - & - & 1.0000 & 1.0000 & - \\
\hline
\end{tabular}

Most of the inputs were calculated from datasets in Ecoinvent, ${ }^{40}$ namely electricity, transport, solvents and most of the reagents. However, FAI and CsI production processes could not be found in databases, it was therefore modelled from information in literature. In particular, the synthesis of FAl was modelled from several reactions with hydrogen cyanide, hydroxylamine, acetic acid and hydroiodic acid as reagents. ${ }^{4,41,42}$ At the same time, CsI was modelled from a process of recovery of Cs from pollucite with sulphuric acid and hydroiodic acid as reagents. ${ }^{43}$ In addition, the characterisation factor of Cs for abiotic depletion potential category was obtained from two different methods to contrast them. The most utilised characterisation factor in this work was extracted from literature. ${ }^{44,45}$ For the sake of presenting a comparison, an updated factor was estimated based on data from 2017, ${ }^{46,47}$ according to the methodology description. ${ }^{44}$

From the stoichiometric coefficients (Table 2) and the amount of perovskite, the amount of each reagent was obtained, which are reported in Table 3. The mass of perovskite was calculated by multiplying the perovskite's density ${ }^{19}$ by the volume of perovskite deposited in the cell. The volume was obtained by multiplying $25 \mathrm{~cm}^{2}$ of substrate area and $500 \mathrm{~nm}$ of thickness of perovskite layer, which were assumed.

Table 3. Inventory of chemicals used for the syntheses of the perovskites $\left(\mu \mathrm{g} / \mathrm{cm}^{2}\right)$.

\begin{tabular}{|l|c|c|c|c|c|}
\hline Reagents/Solvents & $\mathbf{0 . 0 0}$ & $\mathbf{0 . 0 5}$ & $\mathbf{0 . 1 0}$ & $\mathbf{0 . 1 5}$ & Canonical \\
\hline $\mathrm{CsI}$ & 0 & 4.38 & 8.76 & 13.1 & \\
\hline $\mathrm{FAl}$ & 48.1 & 45.7 & 43.3 & 40.9 & \\
\hline $\mathrm{MABr}$ & 6.42 & 6.09 & 5.77 & 5.45 & \\
\hline $\mathrm{MAI}$ & & & & & 52.4 \\
\hline $\mathrm{PbI}_{2}$ & 129 & 128 & 128 & 127 & 152 \\
\hline $\mathrm{PbBr}_{2}$ & 21.0 & 21.6 & 22.1 & 22.6 & \\
\hline $\mathrm{DMF}$ & 799 & 791 & 783 & 774 & \\
\hline $\mathrm{DMSO}$ & 233 & 230 & 228 & 226 & \\
\hline $\mathrm{CB}$ & \multicolumn{7}{|l|}{4440} & & \\
\hline GBL & \multicolumn{7}{|l|}{} & & & 307 \\
\hline
\end{tabular}

The electric consumption of multiple cation/anion perovskite used in the steps detailed in Figure 1 was experimentally determined. The inventory of overall electricity usage for the two 
methods is shown in Table 4. During mixture and annealing steps 16 devices processed simultaneously were assumed.

Table 4.Inventory of electric consumption of devices used for perovskite mixture and deposition.

\begin{tabular}{|l|c|c|}
\hline Step & $\begin{array}{c}\text { Anti-solvent } \\
\text { method }\left(\mathrm{J} / \mathrm{cm}^{2}\right)\end{array}$ & $\begin{array}{c}\text { Conventional } \\
\text { method }\left(\mathrm{J} / \mathrm{cm}^{2}\right)\end{array}$ \\
\hline Mixing & 36 & 171 \\
\hline Spin-coating $(500 \mathrm{rpm})$ & 144 & 20 \\
\hline Spin-coating $(1000 \mathrm{rpm})$ & & 252 \\
\hline Spin-coating $(2000 \mathrm{rpm})$ & 288 & \\
\hline Spin-coating $(6000 \mathrm{rpm})$ & 1647 & 1647 \\
\hline Annealing & 2115 & 2090 \\
\hline Total energy consumption & & \\
\hline
\end{tabular}

Finally, there are two classes of inventory flows left to account for. These are the amount of transportation and the outputs released during the deposition. The amount of transportation was obtained from the distance of the supplier to Castelló (Spain), where the laboratories are located. Solvent releases during perovskite deposition were assumed to be similar to the amounts of solvent used. A complete inventory is described in the supplementary information Tables S1- S7.

\subsection{Economic analysis}

An additional economic analysis was performed in order to support the environmental assessment. For this analysis, chemicals for the synthesis and deposition of perovskite were only considered as transport price is embedded into chemicals' price. The energy consumption flow was not included in the economic analysis due to the great uncertainty of its measurement. Furthermore, the process outputs were supposed void of economic cost. The price in euros of each input was calculated from the amount of each used and its retail price from the main suppliers. Further details are provided in the supplementary information Table S8.

\subsection{Impact categories}

For a comprehensive and thorough comparison, eleven impact categories were chosen, in which the most developed impact models and the most representative categories were rendered, see Table 5. Seven of this group of categories are included in the CML baseline V3.02. ${ }^{44,48}$ These categories are Abiotic depletion (ADP), Abiotic depletion fossil fuels (ADPF), Global warming (GWP), Ozone layer depletion (ODP), Photochemical oxidation (POP), Acidification (AP) and Eutrophication (EP). From these categories, one of the most significant for measuring the environmental performance of a solar energy collector device is Global warming, as one of the main benefits of energy stemming from such devices is the mitigation of greenhouse effect. Nonetheless, the other categories enlisted represent a broad panoply of 
the most concerning categories which must be taken into consideration in order to avoid environmental charge transference, from Global warming category to these categories.

Additionally, four determining categories were chosen. From the Cumulative energy demand method(CED), ${ }^{49}$ the total cradle-to-gate energy invested in the perovskite layer is obtained by adding cumulative energies obtained from sources renewable and non-renewable. This category allows contrasting the energy invested to produce it with the energy obtained from it. Owing to the concerning content of lead in PSCs, it is necessary to introduce into the assessment the impact categories Human toxicity cancer (HTC), Human toxicity non-cancer (HTNC) and Freshwater ecotoxicity (FET) from USEtox V1.04 method. ${ }^{50}$

CML, CED and USEtox methods are incorporated within the SimaPro ${ }^{\circledR}$ 8.0.3.14 software. ${ }^{51}$ In this manuscript, abbreviations listed in Table 5 are used to name the selected impact categories.

Table 5.List of impact categories, their abbreviations, units and methodologies in which they are included.

\begin{tabular}{|c|c|c|c|}
\hline Category & Abbreviation & Unit & Methodology \\
\hline Abiotic depletion potential & ADP & $\mathrm{kg} \mathrm{Sb}$ eq & \multirow{7}{*}{ CML baseline V3.02 } \\
\hline $\begin{array}{l}\text { Abiotic depletion potential, fossil } \\
\text { fuels }\end{array}$ & ADPF & MJ & \\
\hline Climate change potential & GWP & $\mathrm{kg} \mathrm{CO}{ }_{2} \mathrm{eq}$ & \\
\hline Ozone layer depletion potential & ODP & kg CFC-11 eq & \\
\hline Photochemical oxidation potential & POP & $\mathrm{kg} \mathrm{C}_{2} \mathrm{H}_{4} \mathrm{eq}$ & \\
\hline Acidification potential & AP & $\mathrm{kg} \mathrm{SO}_{2} \mathrm{eq}$ & \\
\hline Eutrophication potential & EP & $\mathrm{kg} \mathrm{PO}_{4}{ }^{3-}$ eq & \\
\hline Cumulative energy demand & CED & MJ & Cumulative energy demand V1.09 \\
\hline Human toxicity, cancer effects & HTC & CTUh & \multirow{3}{*}{ Usetox V1.04 } \\
\hline Human toxicity, non-cancer effects & HTNC & CTUh & \\
\hline Freshwater ecotoxicity & FET & CTUe & \\
\hline
\end{tabular}

\section{Results and discussion}

The environmental impact of multiple cation/anion perovskite were compared with the environmental impact of a canonical perovskite, in Figure 2. These outcomes comprise the environmental impacts generated from the materials extraction until the PSC is manufactured, although considering just the effect of perovskite layer as it has been previously commented in section 2.2. The results are plotted in percentage considering the impact of the composition with the largest impact as $100 \%$, been this composition the multiple cation/anion perovskite with $\mathrm{x}=0$, i.e. $M A_{0.17} F A_{0.83} P b\left[I_{0.83} B r_{0.17}\right]_{3}$, for every category but ADP. Alongside with the total impacts including the impact originated by the energy consumption for the preparation of the perovskite layer, results without accounting the energy consumption are also plotted in Figure 2. Energy consumption for the preparation of PSCs at lab scale has been directly measured and in fact it rules most of the impact as can be appreciated in the distribution of 
impacts per type of flow Figure S1. The contribution of energy consumption to the total impact will undoubtedly decrease with the industrial up-scaling process. Consequently, in order to take into account the direct impact of the materials themselves the impact without taking into account the energy consumption have been also calculated and represented in Figure 2 .

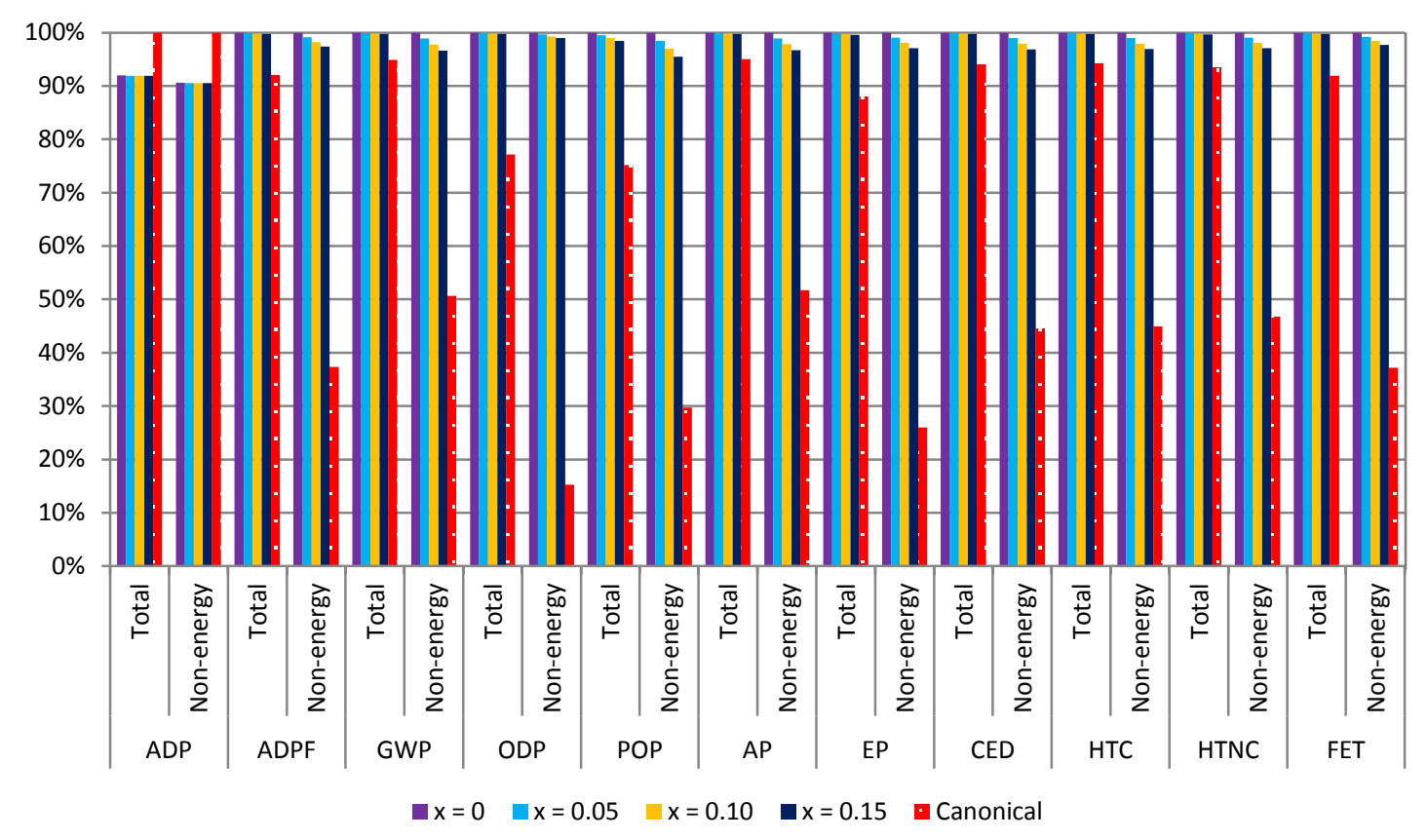

Figure 2.Relative impacts of perovskite layer synthesis and deposition with proportions of Cs of $x=0,0.05,0.10$ and 0.15 at the perovskite cationic position for multiple cation/anion $\boldsymbol{C s}_{\boldsymbol{x}}\left[\boldsymbol{M A}_{\mathbf{0 . 1 7}} \boldsymbol{F A}_{\mathbf{0 . 8 3}}\right]_{(1-x)} \boldsymbol{P b}\left[\boldsymbol{I}_{\mathbf{0 . 8 3}} \boldsymbol{B r}_{\mathbf{0 . 1 7}}\right]_{3}$ compared with the canonical perovskite for total impacts and without taking energy consumption into account. In X-axis are the environmental impact categories.

Outcomes of the comparison of environmental impacts of the four compositions of perovskite containing $\mathrm{Cs}, \mathrm{FA}, \mathrm{MA}, \mathrm{I}$ and $\mathrm{Br}$ with the canonical perovskite, which is composed of just MA and I, are quite homogeneous for all categories, except for ADP category. In general, they show that multiple cation/anion perovskite compositions are more harmful than canonical perovskite, except for ADP where canonical perovskite impact surpasses that of multiple cation/anion perovskites.

A comprehensive table with the absolute outcomes of the five different perovskite composition here compared is available in the supplementary information Tables S9-S13. In addition, the impact distribution of the flows of inputs and outputs of the process of the perovskite synthesis and deposition is presented in the supplementary information, see Figure S1. Total impact results for multiple cation/anion perovskite impacts are very analogous among them. Approximately, the canonical perovskite impact supposes just a $92 \%$ of the multiple cation/anion perovskite with $\mathrm{x}=0$ impact, which is the most harmful among triple cation perovskites for all categories. This fact is true except for ODP, POP and EP categories, where canonical perovskite supposes a $77 \%, 75 \%$ and $87 \%$ of the $\mathrm{x}=0$ perovskite, respectively. The little deviation stems from a slightly larger impact of multiple cation/anion perovskites reagent and energy consumption. 
However, for ADP category impact multiple cation/anion perovskite is predominant, supposing roughly a $92 \%$ respect to the canonical perovskite impact. The reason behind this lies on the fact that the main responsible group of inputs of the impact of ADP category are the synthesis reagents, mainly $\mathrm{Pbl}_{2}$, whose impact is bigger for the canonical perovskite. There is a little difference of impact amongst multiple cation/anion perovskites, as the amount of synthesis reagents used is identical. Generally, for this category energy consumption is not as determinant as for the rest of categories. Although Cs impact is negligible for ADP category and unappreciable for the rest of the categories, its ADP characterisation factor (ADPF) needs a revision because it might be outdated. Due to the ADPF utilised for this study is taken from literature of 2002, ${ }^{44,45}$ ADPF was updated to $2017 .{ }^{46,47}$ Further details about the updating can be seen in the supplementary information.

Nevertheless, the impact due to the different materials and processed employed in the fabrication of multiple cation/anion perovskites in comparison with canonical perovskite is evident when energy consumption is not considered in the total impacts, see Figure 2. $M A_{0.17} F A_{0.83} \mathrm{~Pb}\left[\mathrm{I}_{0.83} \mathrm{Br}_{0.17}\right]_{3}$ is the most harmful perovskite, the impact of multiple cation/anion perovskites decreases as the content of $\mathrm{Cs}$ increases. However, with variations that do not differ more than a $5 \%$ for any category. On the other hand, the impacts of canonical perovskite is just $15-55 \%$ of the impact of $M A_{0.17} F A_{0.83} P b\left[I_{0.83} B r_{0.17}\right]_{3}$ perovskite, the most harmful one, depending on the impact category except for ADP where the canonical perovskite has more impact, for the reason previously commented.

Figure 2 clearly reflect that the canonical perovskite is significantly less harmful than the multiple cation/anion perovskite when energy use is not considered. A closer and more precise view of the contributions of the reagents and the solvents for the deposition of the here studied compositions of multiple cation/anion perovskite in comparison to the canonical perovskite is detailed in Figure 3. In this analysis, the most determining categories to assess PSCs are selected, which are GWP, CED, HTC and HTNC.

Lead reagents are among the most pernicious compounds. For HTC and HTNC categories, $\mathrm{Pbl}_{2}$ is the major contributor to the overall impact, which is attributed to the larger quantity of it, used for the synthesis of the perovskites. However similar impact is produced by the $\mathrm{Pbl}_{2}$ in canonical samples that by the sum of the impacts originated by $\mathrm{Pbl}_{2}$ plus $\mathrm{PbBr}_{2}$ in multiple cation/anion perovskite layers. The huge differences in the impacts among multiple cation/anion and canonical perovskite layers are due to the use in the formers of $C B$ in the anti-solvent method and FAI instead of MAI, where the latest generates less impacts. CB used for the anti-solvent method has a slightly lower impact for HTC and HTNC impacts. However, for GWP and CED categories CB is responsible of the highest contribution to the overall impact, where $\mathrm{Pbl}_{2}$ is the second most contributing compound. The great contribution of CB stems from the fact that its amount used is the highest among all compounds, despite its little impact per $\mathrm{kg}$ in comparison with $\mathrm{Pbl}_{2}$. Impact improvements of a possible optimisation of $\mathrm{CB}$ are analysed in the supplementary information. Results of this analysis disclose that despite the reductions in chlorobenzene usage, except for the ADP category, overall impacts of multiple cation/anion perovskites would not reach the impact extent of the canonical perovskite shown in Figure 2. The up-scaling of anti-solvent technology to move from lab scale cell to large 
substrates is not straightforward at all from the technological point of view. ${ }^{39}$ Here we show that anti-solvent method also has an important deleterious effect on the impacts generated and consequently should be exchanged by a lower impact method in the future commercialization of perovskites.

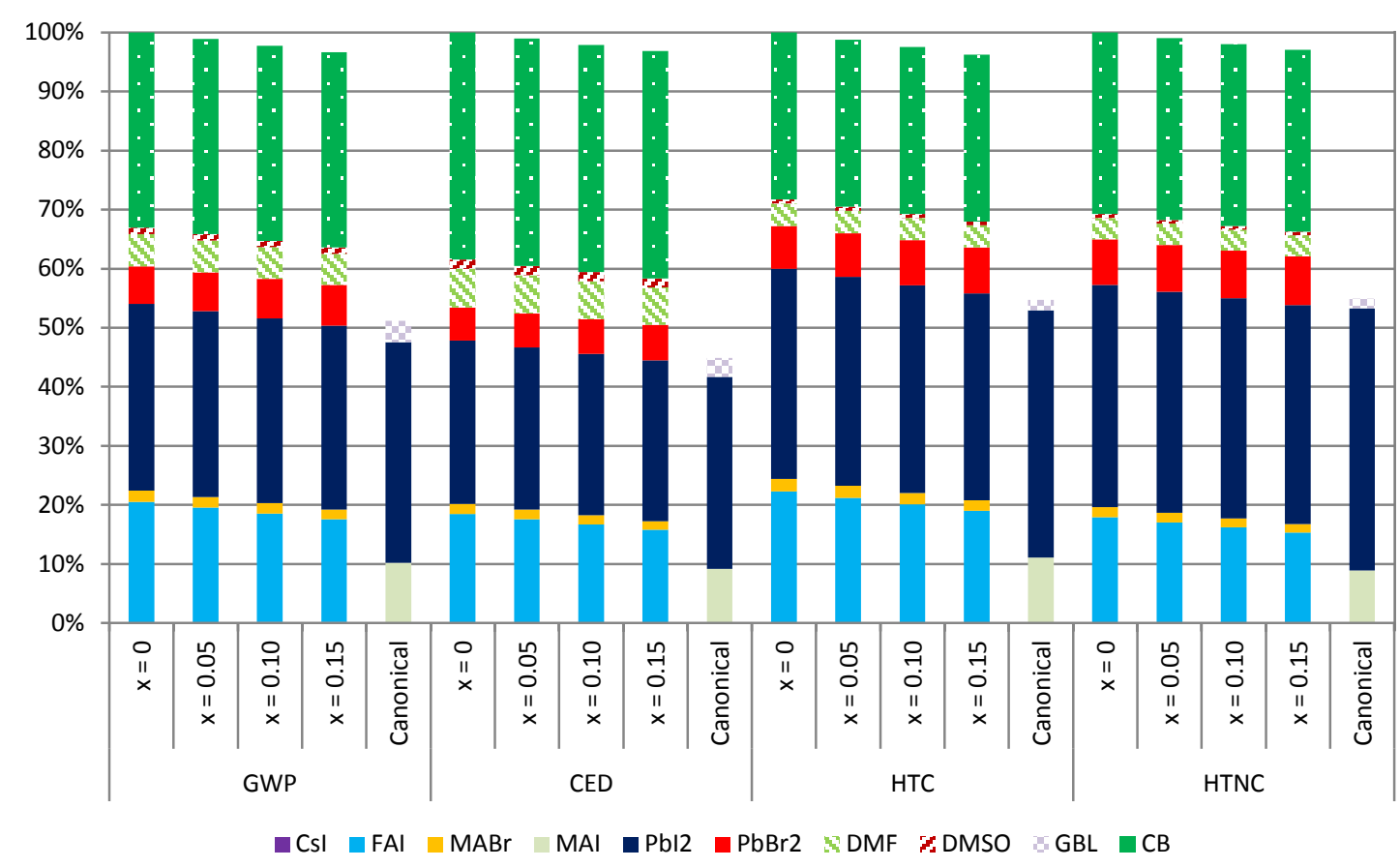

Figure 3. Relative impacts of materials for PSCs with proportions of caesium of $x=0, x=0.05, x=0.10$ and $x=0.15$ at the perovskite cationic position. Impact categories: Global warming potential (GWP), Cumulative energy demand (CED), Human toxicity, cancer (HTC), and Human toxicity, non-cancer (HTNC).

Among the reagents that supply the three cations, FAl emerges as the most adverse, which is also the reagent that mostly varies along compositions and therefore the reagent that eventually determines the result. Most of its impact stems from the energy used to synthesise it, as its synthesis from hydroiodic acid and formamidine acetate is performed in laboratory environment. In particular, the most detrimental step of this process is a final treatment in a vacuum oven at 60 o $\mathrm{C}$ for $24 \mathrm{~h} .{ }^{4}$ By reducing the operational time of this treatment impacts of multiple cation/anion perovskite would not decrease as much as those of the canonical perovskite. Nonetheless, for GWP, CED, HTC and HTNC categories, impact of FAI is less adverse than that of the cation supplier reagent for canonical perovskite (MAI) when this operational time goes below 6 hours.

Meanwhile, contribution of $\mathrm{MABr}$ is vague and contribution of $\mathrm{Cs}$ l is not visible due to a little amount of them is used. Alongside with the fact that more amount of FAl is used for the synthesis of multiple cation/anion perovskite, its impact per $\mathrm{kg}$ of reagent is the highest of the three reagents that supply cations, making the $M A_{0.17} F A_{0.83} P b\left[I_{0.83} B r_{0.17}\right]_{3}$ perovskite the most harmful, where the impact is reduced when $x$ increases due to the fact that less FAl is used as it is partially substituted by Csl. 
Usage of solvents produces a considerable lesser impact respect to the reagents. DMF solvent causes a superior impact than DMSO, both considerably inferior to that of CB. In contrast to preceding works, ${ }^{26,34}$ perovskite deposition solvent impacts are generally of trivial magnitude. This statement is true provided that CB would not be treated as such since it satisfies the extra function of removing solvents used for the deposition. $\mathrm{DMF}, \mathrm{PbBr}_{2}$ and $\mathrm{Csl}$ are the only flows whose impact increases with the Cs content. Meanwhile, the remaining flows impact decreases with the amount of Cs. Moreover, CB impact remains constant due to its amount does not vary along the different compositions.

\subsection{Economic analysis}

In order to complement the analysis of four multiple cation/anion perovskites with the canonical $\mathrm{MAPbl}_{3}$ perovskite, the economic consequences of the usage of reagents and solvents for the perovskites deposition are analysed in Figure 4. For this analysis, use of energy flow is dismissed owing to an unrealistic usage in laboratory environment. In this economic analysis the cost in euros of each reagent and solvent is obtained from its amount used and its retail price, see Table S8 for further details. Note the economic analysis here reported are for cells at lab scale and just considering the cost of the perovskite layer. This fact makes that the cost here reported are overestimated considering a future industrial application. However, it provides important clues about which parts are mostly affecting the final price.

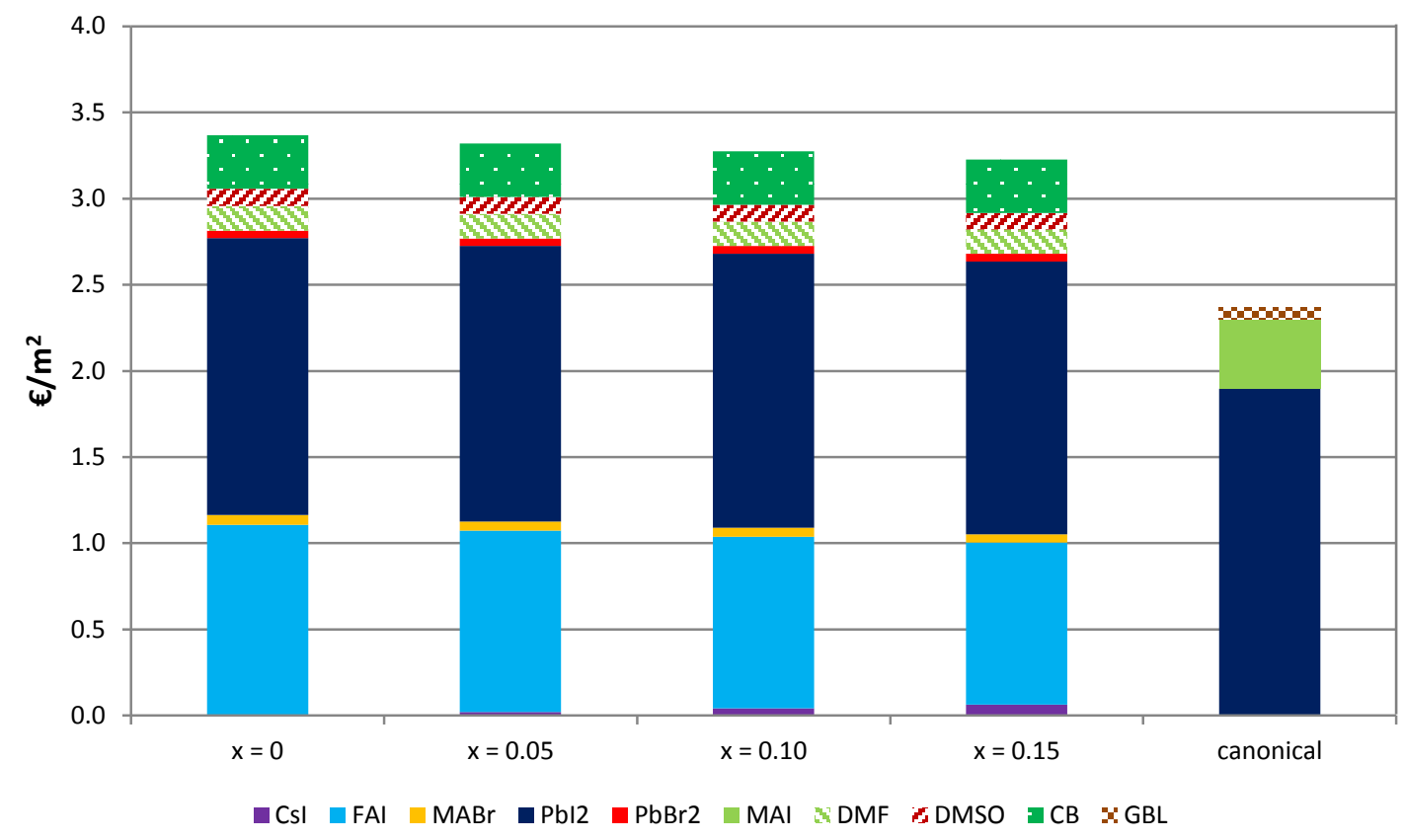

Figure 4. Cost in euros of materials for the deposition of perovskite active layer each of the PSCs analised. Energy is not included in this analysis.

In Figure 4, the canonical perovskite arises as the most economical type by virtue of the lesser quantity of compounds used. The principal compound behind the higher cost of multiple cation/anion perovskites in comparison with the canonical composition is the FAI. In fact, cost of multiple cation/anion perovskites is roughly $1 € / \mathrm{m}^{2}$ higher than that of multiple cation/anion 
perovskite, which matches approximately with the cost of FAI. Furthermore, this difference decreases with the Cs content used favoured by the subsequent reduction in the cost of FAI. Among multiple cation/anion perovskites the cheapest composition is the $\mathrm{x}=0.15$ with the highest content of $\mathrm{CS}$ and consequently the lowest of FA. Despite the determining character of FAl and its highest cost per mass unit, $\mathrm{Pbl}_{2}$ with the second highest cost per mass unit is the most expensive reagent used in all the composition, however in multiple cation/anion perovskite the cost is slightly mitigated by the introduction of $\mathrm{Br}$ anion and the consequent use of $\mathrm{PbBr}_{2}$ precursor, significantly cheaper than $\mathrm{Pbl}_{2}$, see Table S8. DMF and DMSO solvents cost is lower than the $\mathrm{CB}$ cost, nonetheless this three compounds cost is neither important nor determining for the total cost.

Given that PSCs can be an economic source from the energy generated, a cost payback time analysis was performed for the perovskite layer. Due to the canonical perovskite arises as the lower cost perovskite layer respect to the rest of perovskites here analysed, the payback time will be lower for canonical perovskite if the efficiencies of the cells are similar. Multiple cation/anion perovskite can only have the same payback time by an increase of cell efficiency. In Figure 5, the efficiency of a multiple cation/anion perovskite with $\mathrm{x}=0.10$ (the perovskites with the highest reported efficiency in Table 1), left axis, is plotted against the efficiency of perovskite canonical cell in order that both present the same payback time. It has been calculated considering the perovskite layer cost, see Figure 4 , and the price of $1 \mathrm{MJ}$ of electricity in Spain and the assumption of a solar constant of $1 \mathrm{~kW} / \mathrm{m}^{2}$. This analysis calculates the efficiency that should have the perovskite with $x=0.10$ of Cs to recover the money invested on its synthesis and deposition in the same time than the canonical perovskite does. The difference between the efficiencies of multiple cation/anion and canonical perovskite to get the same payback time is represented by the right axis in Figure 6 , to facilitate the comprehension of this analysis. 


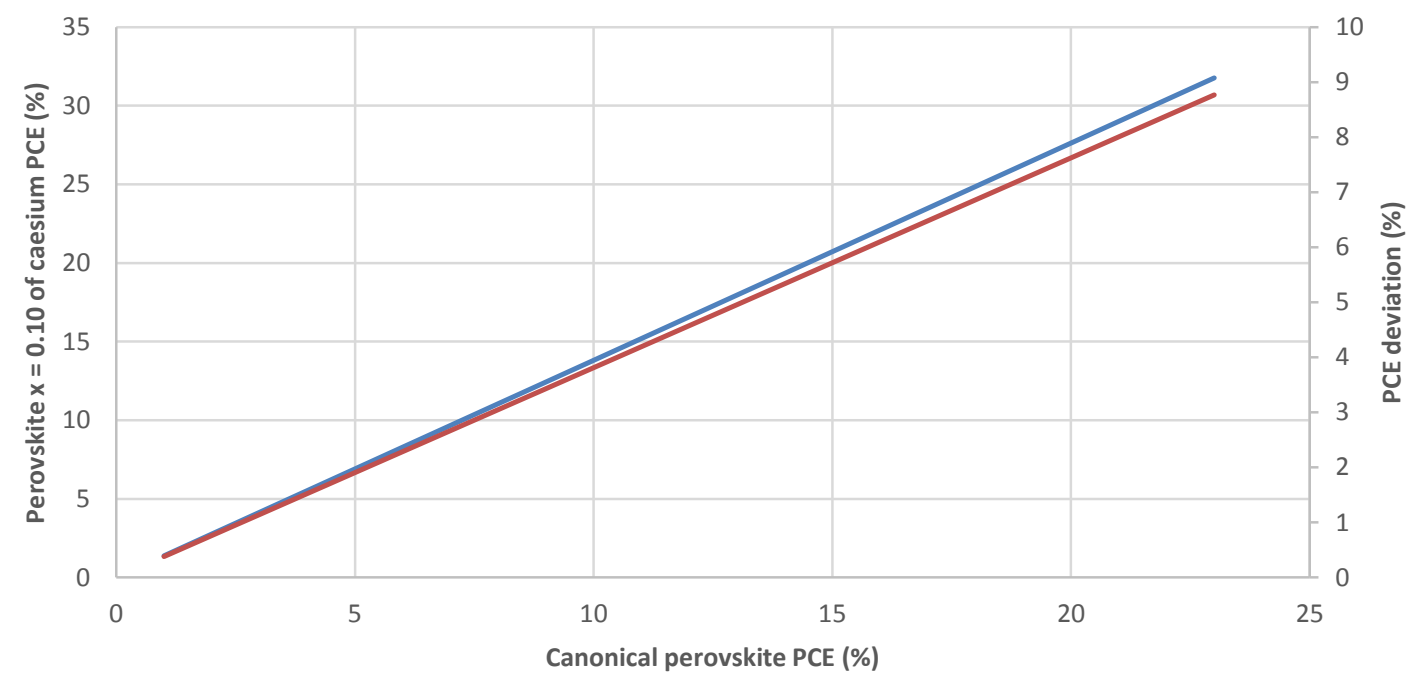

Equivalent cost payback efficiency of perovskite with $\mathrm{x}=0.10$ of caesium PCE (\%)

Deviation between canonical perovskite and its cost payback equivalent for the perovskite with $\mathrm{x}=0.10$ of caesium (\%)

Figure 5. Equal cost payback time for the perovskite with $x=0.1$ of caesium and canonical perovskite PSCs.

The payback cost analysis in Figure 5 reveals that the efficiency necessary to recover the money invested in the synthesis and deposition of a canonical perovskite with and efficiency of $16 \%$, for a perovskite with $x=0.10$ of $C s$ is similar the current published efficiency record of $22.1 \%,{ }^{3}$ i.e. the efficiency of multiple cation/anion perovskite has to be 1.38 the efficiency of the canonical perovskite to make equal the payback cost.

\section{Conclusions}

The outcomes of the comparison of four perovskites containing Cs, formamidinium and methylammonium as cation and $\mathrm{I}$ and $\mathrm{Br}$ as anions to the canonical perovskite with methylammonium cation and just $I$ as anion expose that multiple cation/anion perovskites are harmful for all the impact categories analysed except for abiotic depletion potential (ADP). The impact of multiple cation/perovskite is even more pronounced if the energy used in the cell fabrication is not considered. Two are the main reasons of the higher impact of multiple cation/anion perovskites: The use of the anti-solving method and the utilization of FAI precursor. This work points out that the anti-solving method, that produce outstanding results at lab scale, is not adequate for industrial implementation. The reason behind this is not only owing to technical difficulties of its implementation on larger substrate sizes, but also to the increase of impacts. On the other hand, FA cation is present in the efficiency record PSCs. ${ }^{3-5,10}$ Nevertheless, the FAl chemical used in the multiple cation/anion perovskites synthesis increases significantly the impacts. Moreover, it is the most expensive precursor causing an important increase of the cell cost in comparison with canonical devices using just MA as monovalent cation. The current synthesis of this precursor needs to be optimised in order to reduce these impacts and cost. In contrast, the partial substitution of $\mathrm{I}$ by $\mathrm{Br}$ anions has positive consequences as it has practically no effect in terms of impact, nonetheless reducing the device cost, as $\mathrm{PbBr}_{2}$ is remarkably cheaper than $\mathrm{Pbl}_{2}$. The future utilisation of multiple 
cation/anion in the industrialisation of perovskite process needs a detailed and balanced study of not only efficiency but also impact and cost. For example, here we highlight that a canonical $\mathrm{MAPbl}_{3}$ with $16 \%$ efficiency will be more attractive for industrialisation, as long as it can be prepared with enough stability, than multication cells with FA and with the current published record efficiency of $22.1 \%$ as both present the same payback time but the former exhibits reduced impacts.

\section{Acknowledgements}

We acknowledge financial support from MINECO of Spain under Project MAT2016-76892-C3-1R.

\section{Conflicts of interest}

There are no conflicts to declare.

\section{References}

1 A. Kojima, K. Teshima, Y. Shirai and T. Miyasaka, J. Am. Chem. Soc., 2009, 131, 60506051.

H. J. Snaith, J. Phys. Chem. Lett., 2013, 4, 3623-3630.

3 W. S. Yang, B.-W. Park, E. H. Jung, N. J. Jeon, Y. C. Kim, D. U. Lee, S. S. Shin, J. Seo, E. K. Kim, J. H. Noh and S. II Seok, Science (80-. )., 2017, 356, 1376-1379.

4 W. S. Yang, J. H. Noh, N. J. Jeon, Y. C. Kim, S. Ryu, J. Seo and S. I. Seok, Science (80-. )., 2015, 348, 1234-1237.

5 N. J. Jeon, J. H. Noh, W. S. Yang, Y. C. Kim, S. Ryu, J. Seo and S. II Seok, Nature, 2015, 517, 476-480.

6 T. Leijtens, G. E. Eperon, N. K. Noel, S. N. Habisreutinger, A. Petrozza and H. J. Snaith, Adv. Energy Mater., 2015, 5, 1500963.

7 N.-G. Park, M. Grätzel, T. Miyasaka, K. Zhu and K. Emery, Nat. Energy, 2016, 1, 16152.

8 G. Grancini, C. Roldán-Carmona, I. Zimmermann, E. Mosconi, X. Lee, D. Martineau, S. Narbey, F. Oswald, F. De Angelis, M. Graetzel and M. K. Nazeeruddin, Nat. Commun., 2017, 8, 15684.

9 J. A. Christians, P. Schulz, J. S. Tinkham, T. H. Schloemer, S. P. Harvey, B. J. Tremolet de Villers, A. Sellinger, J. J. Berry and J. M. Luther, Nat. Energy, 2018, 3, 68-74.

10 F. Zhang, S. Wang, X. Li and Y. Xiao, Curr. Nanosci., 2016, 12, 137-156.

11 J. W. Lee, D. J. Seol, A. N. Cho and N. G. Park, Adv. Mater., 2014, 26, 4991-4998. 

1769.

13 N. Pellet, P. Gao, G. Gregori, T. Y. Yang, M. K. Nazeeruddin, J. Maier and M. Grätzel, Angew. Chemie - Int. Ed., 2014, 53, 3151-3157.

14 F. Giordano, A. Abate, J. P. Correa Baena, M. Saliba, T. Matsui, S. H. Im, S. M. Zakeeruddin, M. K. Nazeeruddin, A. Hagfeldt and M. Graetzel, Nat. Commun., 2016, 7, 10379.

15 M. Saliba, T. Matsui, J.-Y. Seo, K. Domanski, J.-P. Correa-Baena, M. K. Nazeeruddin, S. M. Zakeeruddin, W. Tress, A. Abate, A. Hagfeldt and M. Grätzel, Energy Environ. Sci., 2016, 9, 1989-1997.

16 H. Cho, S.-H. Jeong, M.-H. Park, Y.-H. Kim, C. Wolf, C.-L. Lee, J. H. Heo, A. Sadhanala, N. Myoung, S. Yoo, S. H. Im, R. H. Friend and T.-W. Lee, Science (80-. )., 2015, 350, 12221225.

17 D. Bi, W. Tress, M. I. Dar, P. Gao, J. Luo, C. Renevier, K. Schenk, A. Abate, F. Giordano, J.P. Correa Baena, J.-D. Decoppet, S. M. Zakeeruddin, M. K. Nazeeruddin, M. Gra tzel and A. Hagfeldt, Sci. Adv., 2016, 2, e1501170-e1501170.

W. Shockley and H. J. Queisser, J. Appl. Phys., 1961, 32, 510-519.

C. C. Stoumpos, C. D. Malliakas and M. G. Kanatzidis, Inorg. Chem., 2013, 52, 9019-38.

M. Kulbak, D. Cahen and G. Hodes, J. Phys. Chem. Lett., 2015, 6, 2452-2456.

21 F. Fabregat-Santiago, M. Kulbak, A. Zohar, M. Vallés-Pelarda, G. Hodes, D. Cahen and I. Mora-Seró, ACS Energy Lett., 2017, 2, 2007-2013.

23 J.-W. Lee, D.-H. Kim, H.-S. Kim, S.-W. Seo, S. M. Cho and N.-G. Park, Adv. Energy Mater., 2015, 5, 1501310.

24 G. B. Haxel, J. B. Hedrick, G. J. Orris, P. H. Stauffer and J. W. Hendley II, Rare earth elements: critical resources for high technology, 2002.

25 N. Espinosa, L. Serrano-Luján, A. Urbina and F. C. Krebs, Sol. Energy Mater. Sol. Cells, 2015, 137, 303-310.

26 J. Gong, S. B. Darling and F. You, Energy Environ. Sci., 2015, 8, 1953-1968.

27 J. Zhang, X. Gao, Y. Deng, B. Li and C. Yuan, ChemSusChem, 2015, 8, 3882-3891.

28 L. Serrano-Lujan, N. Espinosa, T. T. Larsen-Olsen, J. Abad, A. Urbina and F. C. Krebs, Adv. Energy Mater., 2015, 5, 1501119.

29 I. Celik, Z. Song, A. J. Cimaroli, Y. Yan, M. J. Heben and D. Apul, Sol. Energy Mater. Sol. Cells, 2016, 156, 157-169. 

Corkish, Prog. Photovoltaics Res. Appl., 2017, 25, 679-695.

31 J.-A. Alberola-Borràs, R. Vidal, E. J. Juárez-Pérez, E. Mas-Marzá, A. Guerrero and I. MoraSeró, Sol. Energy Mater. Sol. Cells, 2017.

32 L. Huang, Z. Hu, J. Xu, X. Sun, Y. Du, J. Ni, H. Cai, J. Li and J. Zhang, Sol. Energy Mater. Sol. Cells, 2016, 152, 118-124.

33 B. J. Kim, D. H. Kim, S. L. Kwon, S. Y. Park, Z. Li, K. Zhu and H. S. Jung, Nat. Commun., 2016, 7, 11735.

34 J. Zhang, X. Gao, Y. Deng, Y. Zha and C. Yuan, Sol. Energy Mater. Sol. Cells, 2017, 166, 917.

35 T. Ibn-Mohammed, S. C. L. Koh, I. M. Reaney, A. Acquaye, G. Schileo, K. B. Mustapha and R. Greenough, Renew. Sustain. Energy Rev., 2017, 80, 1321-1344.

36 J. H. Noh, N. J. Jeon, Y. C. Choi, M. K. Nazeeruddin, M. Grätzel and S. II Seok, J. Mater. Chem. A, 2013, 1, 11842.

37 F. Consoli, Guidelines for life-cycle assessment: a code of practice, Society of Environmental Toxicology and Chemistry, Brussels, Belgium, 1993.

38 Environ. Sci. Pollut. Res., 1994, 1, 55-55.

39 Y. Jiang, M. R. Leyden, L. Qiu, S. Wang, L. K. Ono, Z. Wu, E. J. Juarez-Perez and Y. Qi, Adv. Funct. Mater., 2018, 28, 1703835.

40 R. Frischknecht, N. Jungbluth, H. J. Althaus, G. Doka, R. Dones, T. Heck, S. Hellweg, R. Hischier, T. Nemecek, G. Rebitzer and M. Spielmann, Int. J. Life Cycle Assess., 2005, 10, 3-9.

41 F. Eloy, R. Lenaers and C. Moussebois, Helv. Chim. Acta, 1962, 45, 437-441.

42 W. Lossen and P. Schifferdecker, Justus Liebig's Ann. der Chemie und Pharm., 1873, 166, 295-320.

43 P. M. Brown, M. C. Northrup and F. Bakke, 2002.

44 H. de Bruijn, R. van Duin and M. A. J. Huijbregts, Handbook on Life Cycle Assessment, Springer Netherlands, Dordrecht, 2002, vol. 7.

45 M. Gorrée, J. B. Guinée, G. Huppes and L. van Oers, Int. J. Life Cycle Assess., 2002, 7, 158-166.

46 J. Emsley, Nature's Building Blocks: An A-Z Guide to the Elements, Oxford University Press, Oxford, 2001.

47 U.S. Geological Survey, Mineral Commodities Summaries 2017, Reston, Virginia, 2017. 
48 O. Jolliet, M. Margni, R. Charles, S. Humbert, J. Payet, G. Rebitzer and R. Rosenbaum, Int. J. Life Cycle Assess., 2003, 8, 324-330.

49 R. Frischknecht, N. Jungbluth, H.-J. Althaus, G. Doka, R. Dones, T. Heck, S. Hellweg, R. Hischier, T. Nemecek, G. Rebitzer and M. Spielmann, Int. J. Life Cycle Assess., 2004, 10, 3-9.

50 R. K. Rosenbaum, T. M. Bachmann, L. S. Gold, M. A. J. Huijbregts, O. Jolliet, R. Juraske, A. Koehler, H. F. Larsen, M. MacLeod, M. Margni, T. E. McKone, J. Payet, M. Schuhmacher, D. van de Meent and M. Z. Hauschild, Int. J. Life Cycle Assess., 2008, 13, 532-546.

51 Pré Sustainability, 2016. 